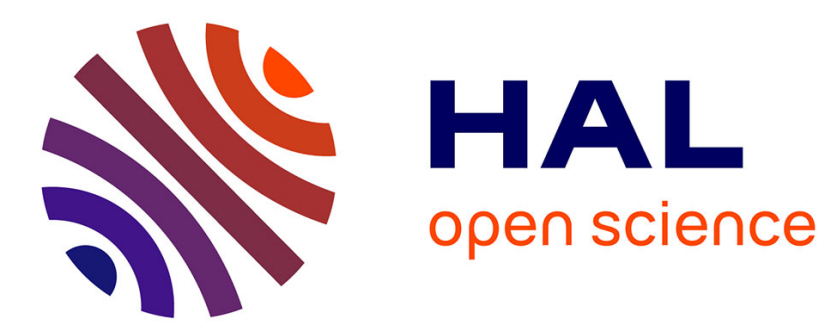

\title{
AFM study of casein micelles cross-linked by genipin: effects of acid $\mathrm{pH}$ and citrate
}

Naaman Francisco Nogueira Silva, Asma Bahri, Fanny Guyomarc'H, Eric Beaucher, Frederic Gaucheron

\section{- To cite this version:}

Naaman Francisco Nogueira Silva, Asma Bahri, Fanny Guyomarc'H, Eric Beaucher, Frederic Gaucheron. AFM study of casein micelles cross-linked by genipin: effects of acid $\mathrm{pH}$ and citrate. Dairy Science \& Technology, 2015, 95 (1), pp.75-86. 10.1007/s13594-014-0199-9 . hal-01123275v2

\section{HAL Id: hal-01123275 \\ https://hal.science/hal-01123275v2}

Submitted on 24 Feb 2016

HAL is a multi-disciplinary open access archive for the deposit and dissemination of scientific research documents, whether they are published or not. The documents may come from teaching and research institutions in France or abroad, or from public or private research centers.
L'archive ouverte pluridisciplinaire HAL, est destinée au dépôt et à la diffusion de documents scientifiques de niveau recherche, publiés ou non, émanant des établissements d'enseignement et de recherche français ou étrangers, des laboratoires publics ou privés.

$$
\text { Copyright }
$$




\title{
AFM study of casein micelles cross-linked by genipin: effects of acid $\mathrm{pH}$ and citrate
}

\author{
N. Nogueira Silva • A. Bahri • F. Guyomarc'h • \\ E. Beaucher • F. Gaucheron
}

Received: 15 May 2014 / Revised: 18 September 2014 / Accepted: 2 October 2014

(C) INRA and Springer-Verlag France 2014

\begin{abstract}
Casein micelles (CMs) are supramolecular structures highly dependent on their mineral content, especially colloidal calcium phosphate. When colloidal calcium phosphate is removed, the micellar structures dissociate and release minerals and casein molecules in the continuous phase. The aim of this work was to study the effects of solubilization of the colloidal calcium phosphate induced by acidification or addition of sodium citrate $\left(100 \mathrm{mmol} . \mathrm{L}^{-1}\right)$ on the structure of cross-linked CMs using atomic force microscopy (AFM). AFM was used to determine the dimensional characteristics, height, diameter, and contact angle of control and cross-linked CMs. To this end, micellar suspensions were cross-linked by genipin and then acidified or demineralized. Colloidal calcium was solubilized, and the results showed that the cross-linked CMs retained more calcium than control CMs. The AFM analysis revealed that control CMs were deformed after immobilization and shrunk upon acidification. As control CMs dissociated in the presence of citrate, dimensional characteristics were not determined by AFM. The crosslinked CMs were also deformed on immobilization but to a lesser extent than control ones. The dimensional characteristics of cross-linked CMs were not modified by acidification. Conversely, demineralization by citrate induced structural rearrangement of the micellar structures. The higher structural resistance of cross-linked CMs was related to intramicellar cross-links between basic amino acids (lysyl and arginyl residues) present in casein molecules. Although AFM was performed in the air, it allowed us to know how the ionic environment modulates the intrinsic nanomechanical properties of CMs.
\end{abstract}

Keywords Casein micelles $\cdot$ Calcium phosphate $\cdot$ Colloid $\cdot$ Cross-linking $\cdot$ Atomic force microscopy $\cdot$ Citrate $\cdot \mathrm{pH}$ - structure

This paper is part of the special issue dedicated to the 2nd International Symposium on Minerals \& Dairy Products (MADP2014) held on 26-28th February 2014 in Auckland, New Zealand.

N. N. Silva · A. Bahri · F. Guyomarc'h • E. Beaucher • F. Gaucheron $(\bowtie)$

INRA, UMR1253, Science et Technologie du Lait et de l'CEuf, 35042 Rennes, France

e-mail: Frederic.Gaucheron@rennes.inra.fr

N. N. Silva $\cdot$ A. Bahri $\cdot$ F. Guyomarc'h $\cdot$ E. Beaucher $\cdot$ F. Gaucheron

Agrocampus Ouest, UMR 1253, Science et Technologie du Lait et de l'Oeuf, 35042 Rennes, France

Published online: 05 November 2014 


\section{Introduction}

In milk, the casein micelles (CMs) are naturally present as supramolecular aggregates of about $200 \mathrm{~nm}$ of diameter, which are porous, highly hydrated, negatively charged, and sterically stabilized by an external layer of K-casein (Fox 2003; De Kruif and Holt 2003). In terms of composition, CMs contain casein molecules $\left(\alpha_{\mathrm{s} 1^{-}}, \alpha_{\mathrm{s} 2^{-}}, \mathrm{k}-\right.$ and $\beta$ casein), water, and minerals (mainly calcium phosphate) (Walstra et al. 2010). The minerals associated with $\mathrm{CMs}$, called colloidal calcium phosphate (CCP), represent 6$8 \%(w / w)$ in the dry matter (Fox 2003). The CCP includes two main forms of mineral association, (i) the cations bound to acid residues of casein molecules (glutamyl and aspartyl) and (ii) the nanoclusters of calcium phosphate. The latter are present as amorphous structures of about $2.5 \mathrm{~nm}$ surrounded by the phosphoseryl residues of $\alpha_{\mathrm{s} 1^{-}}, \alpha_{\mathrm{s} 2^{-}}$, and $\beta$-caseins (Holt et al. 1998). The CCP exists in a dynamic equilibrium with calcium phosphate present in the continuous phase. This equilibrium depends on the physicochemical conditions, e.g., temperature, $\mathrm{pH}$, presence of different minerals, and ionic strength (Holt et al. 1981; Gaucheron 2005).

The integrity and stability of the supramolecular structure of CMs are strongly associated with their mineral content, especially CCP. When calcium-chelating agents (e.g., citrate, EDTA, polyphosphate) are added to milk or micellar suspension, they induce solubilization of CCP with consequent dissociation of CMs due to internal electrostatic repulsion (Lin et al. 1972; Holt 2004). Acidification of milk or micellar suspensions also induces solubilization of CCP (Le Graët and Brulé 1993), but the structure of $\mathrm{CMs}$ is maintained until reaching $\mathrm{pH} \sim 5$ due to the strength of the hydrophobic interactions between the casein molecules (Horne 2009). Nevertheless, the negative charges of CMs are titrated away during acidification, and the solvency of the external layer of $\mathrm{K}$-casein is progressively reduced. Consequently, the stability of the CMs is diminished, and they coagulate around pH 5 (Tuinier and De Kruif 2002; De Kruif and Holt 2003).

It was already shown that the integrity of the structure of CMs with respect to their mineral fraction can be improved by an internal and covalent cross-linking of caseins by transglutaminase (Huppertz and de Kruif 2008). Recently, it was demonstrated that CMs can also be cross-linked by a natural molecule called genipin (GP) (Nogueira Silva et al. 2014). GP is an aglycone obtained from the hydrolysis of an iridoid glycoside, called geniposide, extracted from the fruits of Gardenia jasminoides (Endo and Taguchi 1973). GP reacts with primary amine groups of lysyl or arginyl residues, forming blue pigments (Lee et al. 2003). The study of Nogueira Silva et al. (2014) showed that the cross-linking of CMs by GP was intramicellar. Compared with native CMs, the cross-linked CMs were smaller, more negatively charged, and presented smoother surface when analyzed by scanning electron microscopy. Dynamic light scattering results revealed that cross-linked CMs did not dissociate neither in the presence of citrate $\left(100 \mathrm{mmol} . \mathrm{L}^{-1}\right)$ nor urea $\left(8 \mathrm{~mol} . \mathrm{L}^{-1}\right)$ but swelled in the presence of both chemicals.

Historically, many analytical techniques have been employed to apprehend the structural aspects of CMs (Dalgleish 2011). Among these techniques, atomic force microscopy (AFM) has been successfully used to study the changes on the structure of CMs upon modifications of the physicochemical conditions. Uricanu et al. (2004) applied AFM (in liquid conditions) to determine the elastic properties of CMs and 
observed that these particles were stiffer on increasing temperature. Ouanezar et al. (2012) used AFM (in liquid and dry conditions) and clearly highlighted the raspberrylike appearance of CMs. Additionally, these authors noticed that CMs decreased in size and lost their external roughness upon acidification at $\mathrm{pH} 5$.

The aim of this work was to study the effects of CCP removal by acidification or addition of sodium citrate, known as a calcium-chelating agent, on the structure of control and cross-linked CMs using AFM. To this end, suspensions of purified CMs were previously cross-linked by GP at neutral $\mathrm{pH}$ (7.1). Then, the suspensions were acidified or demineralized, and the consequent solubilization of CCP was monitored by analyzing the calcium concentration in the continuous phase of the suspensions. The new dimensional characteristics, height, width, and apparent contact angle of control and cross-linked CMs, were evaluated by AFM. The 2D and 3D AFM images illustrate the particle modification.

\section{Methods}

\section{$2.1 \mathrm{GP}$ and $\mathrm{CMs}$}

GP was purchased from Challenge Bioproducts Co., Ltd (Yun-Lin Hsien, Taiwan, China) with a purity of $98 \%$. GP was dissolved in a mixture of 74:26 (w/w) HEPES buffer and absolute ethanol to have a stock solution at $200 \mathrm{mmol. \textrm {L } ^ { - 1 }}$.

$\mathrm{CM}$ powder was used as $\mathrm{CM}$ model free of whey proteins, peptides, and free amino acids. This CM powder was obtained by microfiltration of raw skimmed milk $(0.1 \mu \mathrm{m}$ cutoff), followed by diafiltration against deionized water (Pierre et al. 1992) and spraydrying (Schuck et al. 1994). The micellar suspensions were obtained by dispersing the $\mathrm{CM}$ powder at $62.5 \mathrm{~g} . \mathrm{L}^{-1}$ of casein in a buffer solution containing $50 \mathrm{mmol} . \mathrm{L}^{-1}$ of $4-(2-$ hydroxyethyl)-1-piperazine ethane sulfonic acid (HEPES buffer), $2 \mathrm{mmol} \cdot \mathrm{L}^{-1} \mathrm{CaCl}_{2}$ at pH 7.10. Sodium azide at 0.25 g.L $\mathrm{L}^{-1}$ (Sigma, St. Louis, USA) was added to prevent microbial growth. The rehydration of CMs was achieved by stirring the suspensions for $60 \mathrm{~h}$ at room temperature.

\subsection{Cross-linking of CMs by GP}

Micellar suspensions of CMs and GP solution were mixed to have final concentrations of 50 g. $\mathrm{L}^{-1}$ of caseins and 40 mmol.L $\mathrm{L}^{-1}$ GP. A control sample without GP was treated in the same conditions. The dilution caused by the addition of the solution GP was corrected by adding HEPES buffer and absolute ethanol in control suspensions.

The reaction between CMs and GP was carried out as described by Nogueira Silva et al. (2014). Briefly, the reaction was performed at $50{ }^{\circ} \mathrm{C}$ for $24 \mathrm{~h}$. Then, samples were kept at $4{ }^{\circ} \mathrm{C}$ for $26 \mathrm{~h}$ prior to analyses. The reaction between casein molecules and GP was confirmed by the development of a blue color measured at $605 \mathrm{~nm}$ (spectrometer Uvikon 922 Kontron, Milan, Italy) after dilution of 1:33 (v/v) in HEPES buffer (Lee et al. 2003).

2.3 Acidification or citrate addition to control and cross-linked CMs

Both micellar suspensions (control and cross-linked CMs) were acidified at $\mathrm{pH}$ 6.7, 6.4, 5.8, 5.5, and 5.2 by adding 1 mol. $\mathrm{L}^{-1} \mathrm{HCl}(\mathrm{pH} 7.1$ was the $\mathrm{pH}$ of non-acidified 
samples) or demineralized by addition of $1 \mathrm{~mol} . \mathrm{L}^{-1}$ sodium citrate to reach final concentrations of sodium citrate of $10,20,30,40,50$, and $100 \mathrm{mmol}^{-1}$. The dilution effect caused by the addition of $\mathrm{HCl}$ or sodium citrate was corrected. All experiments were conducted twice, and analyses were performed in triplicate.

\subsection{Analysis of control and cross-linked CMs}

\subsubsection{Total and soluble calcium concentrations}

Calcium concentration was measured by atomic absorption spectrometry (Varian 220FS spectrometer, Les Ulis, France) as described by Brulé et al. (1974). Total calcium concentration was determined directly in the micellar suspensions. Concentration of soluble calcium was measured in the ultrafiltrates of the suspensions, obtained using Vivaspin 20 (molecular weight cutoff $=10 \mathrm{kDa}$; Vivascience, Palaiseau, France) centrifuged at $1,800 \mathrm{~g}$ for $1 \mathrm{~h}$ at $20^{\circ} \mathrm{C}$.

\subsubsection{Size distribution and hydrodynamic diameter $\left(D_{h}\right)$ of control and cross-linked CMs}

Size distribution and the average hydrodynamic diameter $\left(D_{\mathrm{h}}\right)$ were measured by dynamic light scattering (DLS) on a Zetasizer Nano ZS (Malvern Instruments, Worcestershire, UK). Measurements were carried out at a scattering angle of $173^{\circ}$ and a wavelength of $633 \mathrm{~nm}$. The average $D_{\mathrm{h}}( \pm 5 \mathrm{~nm})$ was calculated on the intensity distribution using the Stokes-Einstein relation and assuming that particles have a spherical shape. Micellar suspensions were previously diluted at 1:50 ( $/ / v)$ in 50 mmol.L $\mathrm{L}^{-1}$ HEPES and 2 mmol.L $\mathrm{L}^{-1} \mathrm{Ca}$ at $\mathrm{pH} 7.10$, filtered on a membrane with a pore size of $0.45 \mu \mathrm{m}$ to eliminate possible dust particles and left at $20{ }^{\circ} \mathrm{C}$ for $20 \mathrm{~min}$. The viscosity of the solution was $1.003 \mathrm{mPa}^{-1}{ }^{-1}$ at $20^{\circ} \mathrm{C}$, and the refractive index of the solvent was 1.333 .

\subsubsection{AFM analysis of control and cross-linked CMS}

Sample immobilization CMs and cross-linked CMs were immobilized on glass surfaces using carbodiimide chemistry (Uricanu et al. 2004). Briefly, gold-sputtered glass chips were immersed into an ethanolic solution of 2 mmol. $\mathrm{L}^{-1} 11$-mercapto-1undodecanoic acid for $18 \mathrm{~h}$ to produce a self-assembled monolayer (SAM) of carboxyl groups. The chips were extensively rinsed with ethanol and then distilled water and immersed into equal-volume solution of $0.4 \mathrm{mol.L^{-1 }} N$-ethyl-dimethylaminopropyl carbodiimide (EDC) and $0.1 \mathrm{~mol} . \mathrm{L}^{-1} \mathrm{~N}$-hydroxysuccinimide (NHS) for $15 \mathrm{~min}$. They were rinsed with distilled water and immediately immersed into the sample suspensions for $1 \mathrm{~h}$. The chips were finally rinsed with 50 mmol.L ${ }^{-1}$ HEPES buffer at $\mathrm{pH} 7.1$ and dried in a desiccator.

For acid conditions, the immobilized CMs were equilibrated at room temperature in 50 mmol. $\mathrm{L}^{-1}$ HEPES at $\mathrm{pH} 5.2$ and then dried in a desiccator.

For demineralization conditions, $\mathrm{CMs}$ that were previously demineralized using $100 \mathrm{mmol} . \mathrm{L}^{-1}$ sodium citrate at $20^{\circ} \mathrm{C}$ for $2 \mathrm{~h}$ were immobilized as described above, rinsed with 50 mmol. $\mathrm{L}^{-1}$ HEPES buffer at $\mathrm{pH} 7.1$, and dried in a desiccator. 
Image acquisition Imaging of the immobilized particles was conducted according to Ouanezar et al. (2012) using an MFP3D-BIO AFM (Asylum Research, Santa Barbara, USA) operated in tapping mode at room temperature. Images were acquired by means of AC240TS silicon probes (Olympus, Tokyo, Japan; nominal spring constant of $\sim 2 \mathrm{~N} . \mathrm{m}^{-1}$; radius of curvature of $\sim 9 \mathrm{~nm}$ ), with applied forces of about $40 \mathrm{nN}$, and a resonance frequency of $70 \mathrm{kHz}$. The scan rate was $0.8 \mathrm{~Hz}$. The areas of the scanned surfaces varied from $2 \times 2$ to $10 \times 10 \mu \mathrm{m}$. The Igor software (Asylum Research, Santa Barbara, USA) was used to calculate diameter (at the basis of the particles) and height (h) of each particle.

Estimation of the apparent contact angle ( $\theta$ ) By using AFM, it is possible to estimate the apparent contact angle $(\theta)$ between a particle and the solid surface from the height $(h)$ and width $(w)$ of the individual particle as the following equation: $\theta=\cos ^{-1}(1-h / w)$ (Nguyen et al. 2003; Helstad et al. 2007). Here, the concept of apparent contact angle $\theta$ was used to estimate the deformation of spherical particles upon adsorption onto a flat surface, which has been shown to relate to the elastic modulus of polymer particles (Evangelopoulos et al. 2012). Hence, any change in the apparent $\theta$ of immobilized CMs upon modification of their ionic environment is expected to yield information on changes in their intrinsic nanomechanical properties and/or structure. To this end, it was necessary to consider that CMs are soft polymer particles, whose structure is dependent on external stimuli. As convolution of the AFM probe yields larger error on $w$ than on $h$, the contact angle was referred as apparent $\theta$. The results of AFM were analyzed by the Student's $t$ test after verifying the equality of variances by the $F$-test.

\section{Results and discussion}

\subsection{Characterization of control and cross-linked CMs at $\mathrm{pH} 7.10$}

The concentrations of total calcium in the micellar suspensions of control and crosslinked CMs were 42.5 and $41.6 \mathrm{mmol} . \mathrm{L}^{-1}$, respectively. These results were in accordance with Schuck et al. (1994).

Figure 1 shows similar size distributions for control and cross-linked CMs by DLS. The diameters of particles for both samples ranged from $\sim 70$ to $450 \mathrm{~nm}$, and no aggregate was observed. The size distribution was in accordance with De Kruif and Holt (2003), who described the size of CMs as a log-normal distribution, with diameters ranging from $\sim 80$ to $550 \mathrm{~nm}$ and an average of about $200 \mathrm{~nm}$.

The $D_{\mathrm{h}}$ of control CMs was $174 \mathrm{~nm}$, and it was in close agreement with the value of $175 \mathrm{~nm}$ obtained by Glantz et al. (2010) and $179 \mathrm{~nm}$ by Nogueira Silva et al. (2014). The $D_{\mathrm{h}}$ of cross-linked CMs was $157 \mathrm{~nm}$. This value is in accordance with previous results obtained by Nogueira Silva et al. (2014), who determined an average $D_{\mathrm{h}}$ of $160 \mathrm{~nm}$ for cross-linked CMs at similar reaction conditions, i.e., same reaction time and molar proportion between GP and caseins. The reduction in the $D_{\mathrm{h}}$ of cross-linked CMs compared to control CMs (Fig. 1) was attributed to an anchorage of the external layer of $\mathrm{K}$-casein onto the surface of CMs (Nogueira Silva et al. 2014). 


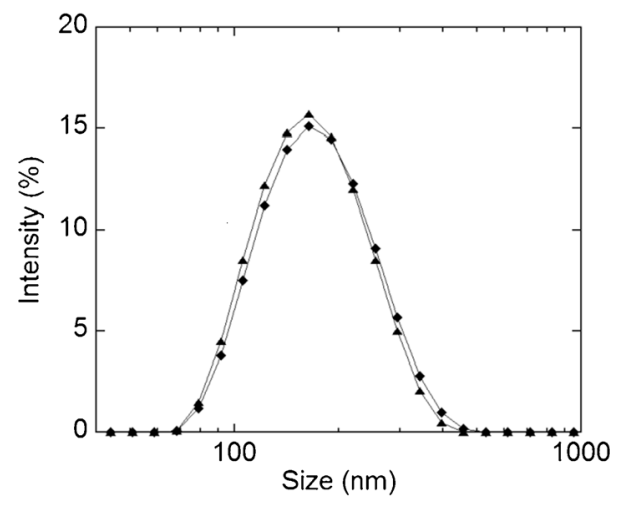

Fig. 1 Particle size distribution as a function of intensity (\%) of the scattered light of the suspensions containing control (diamond) and cross-linked (triangle) CMs at pH 7.1

The AFM results for $w, h$, and apparent $\theta$ of control and cross-linked CMs at $\mathrm{pH} 7.1$ are described in Table 1. The $w$ of the immobilized control CMs (103 nm) agrees with the literature (Gebhardt et al. 2011). However, the control CMs were $\sim$ fourfold wider than high, which reflected in a low value for the apparent $\theta$ determined namely $\sim 40^{\circ}$. These results support the fact that CMs could be deformed on adsorption (Helstad et al. 2007; Ouanezar et al. 2012). Although CMs are physically stable lyophilic colloids (Walstra et al. 2010), the lack of covalent bonds in their core makes them susceptible to destructuration regarding the chemical environment. Thus, an internal cross-linking of CMs is intended to change this scenario.

The cross-linked CMs were significantly higher and narrower than control CMs with an apparent angle of $60^{\circ}$ (Table 1 -comparison 1). These differences were expected and confirmed that cross-linked CMs were more elastic than control CMs. Nevertheless, these cross-linked CMs were still deformable particles, since a perfect elastic sphere immobilized on a surface and imaged with a $9^{\circ}$ AFM tip would exhibit an apparent $\theta$ of about $80^{\circ}$. A visual illustration of these calculated dimensions is shown in Fig. 2 as 2D and 3D images of control and cross-linked CMs.

Table 1 Comparisons of width $(w)$, height $(h)$, and apparent contact angle $(\theta)$ of control and cross-linked CMs determined by AFM in different physicochemical conditions

\begin{tabular}{|c|c|c|c|c|c|c|c|c|}
\hline \multirow[t]{2}{*}{ Samples } & \multirow{2}{*}{$\begin{array}{l}\text { Number } \\
\text { of particles } \\
\text { analyzed }\end{array}$} & \multirow[t]{2}{*}{$w(\mathrm{~nm})$} & \multirow[t]{2}{*}{$h(\mathrm{~nm})$} & \multirow[t]{2}{*}{$\theta\left(^{\circ}\right)$} & \multicolumn{4}{|c|}{ Comparisons } \\
\hline & & & & & 1 & 2 & 3 & 4 \\
\hline Control CMs pH 7.1 & 732 & $103 \pm 68$ & $25 \pm 15$ & $42 \pm 6$ & $\mathrm{a}$ & $\mathrm{a}$ & & \\
\hline Cross-linked CMs pH 7.1 & 632 & $73 \pm 42$ & $39 \pm 31$ & $60 \pm 14$ & $\mathrm{~b}$ & & $\mathrm{a}$ & $\mathrm{a}$ \\
\hline Control CMs pH 5.2 & 581 & $85 \pm 59$ & $13 \pm 9$ & $33 \pm 6$ & & $\mathrm{~b}$ & & \\
\hline Cross-linked CMs pH 5.2 & 919 & $69 \pm 37$ & $38 \pm 25$ & $62 \pm 12$ & & & $\mathrm{a}$ & \\
\hline $\begin{array}{l}\text { Cross-linked CMs with } 0.1 \\
\text { mol.L } \mathrm{L}^{-1} \text { sodium citrate }\end{array}$ & 836 & $91 \pm 70$ & $33 \pm 28$ & $48 \pm 10$ & & & & $\mathrm{~b}$ \\
\hline
\end{tabular}

In the last four columns, the dimensions were statistically compared. The lines indicated by the same letter were not significantly different at $P<0.05$ with respect to $w, h$, and $\theta$. Control CMs were not observed by AFM in the presence of $0.1 \mathrm{~mol} . \mathrm{L}^{-1}$ sodium citrate 

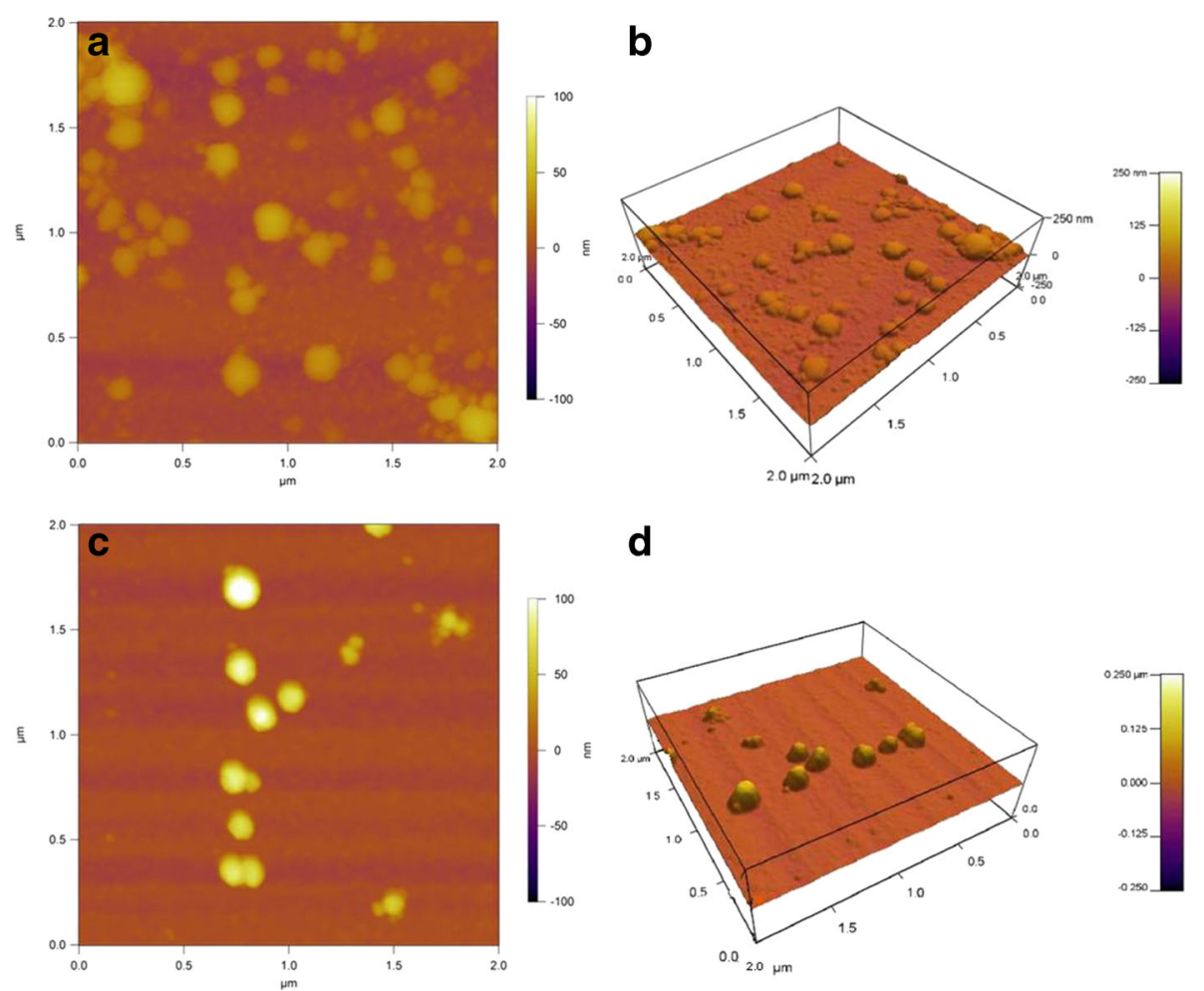

Fig. 2 AFM images of control CMs in $\mathbf{a} 2 \mathrm{D}$ and $\mathbf{b} 3 \mathrm{D}$ at $\mathrm{pH} 7.1$ and cross-linked $\mathrm{CMs}$ in $\mathbf{c} 2 \mathrm{D}$ and $\mathbf{d} 3 \mathrm{D}$ at $\mathrm{pH} 7.1$

Note that $w$ and $h$ dimensions of all particles (control and cross-linked CMsTable 1) determined by AFM were smaller than $D_{\mathrm{h}}$ determined by DLS (Fig. 1). The reason of this difference is that $D_{\mathrm{h}}$ was calculated from DLS distribution on intensity, not volume or number; furthermore, the decrease can also be assigned to the dehydration experienced by particles during sample preparation in AFM (Ouanezar et al. 2012).

\subsection{Acidification of control and cross-linked CMs}

\subsubsection{Calcium solubilization}

The salt distribution between the continuous and colloidal phases of milk is strongly dependent on $\mathrm{pH}$. The main species affecting the ionic equilibrium are $\mathrm{Ca}^{2+}$ and $\mathrm{HPO}_{4}{ }^{2-}$ (Holt 2004). Indeed, the continuous phase of milk or CM suspensions is saturated with respect to $\mathrm{CaHPO}_{4}\left(0.6 \mathrm{mmol} . \mathrm{L}^{-1}\right)$. When $\mathrm{H}^{+}$ions are added to these systems, they preferentially form $\mathrm{H}_{2} \mathrm{PO}_{4}{ }^{-}$due to their greater affinity to ions $\mathrm{HPO}_{4}{ }^{2-}$ compared to ions $\mathrm{Ca}^{2+}$ (Holt et al. 1981). Thus, $\mathrm{CaHPO}_{4}$ dissociates in order to reestablish the chemical equilibrium with $\mathrm{Ca}^{2+}$ and $\mathrm{HPO}_{4}{ }^{2-}$. As a consequence of the $\mathrm{pH}$ decrease, the continuous phase becomes less saturated in $\mathrm{CaHPO}_{4}$, and $\mathrm{CCP}$ is solubilized.

Figure 3 illustrates the solubilization of calcium as a function of $\mathrm{pH}$ for both types of casein suspensions. The initial concentration of soluble calcium for the suspension of 


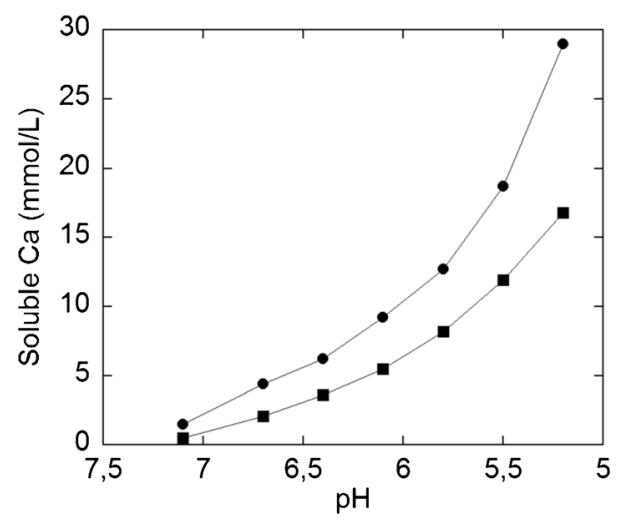

Fig. 3 Concentration of soluble calcium as a function of the $\mathrm{pH}$ of micellar suspensions. Control (circle) and cross-linked (square) CMs

control CMs was 1.5 mmol. $\mathrm{L}^{-1}$ at $\mathrm{pH} 7.1$ and reached 29.0 mmol.L $\mathrm{L}^{-1}$ at $\mathrm{pH}$ 5.2. Le Graët and Brulé (1993) acidified milk from pH 6.7 to 5.2 and showed that $72 \%$ of colloidal calcium was solubilized. In this work, the solubilization of colloidal calcium reached $67 \%$ for the suspensions of control $\mathrm{CMs}$ at $\mathrm{pH} 5.2$ (Fig. 3), which can be considered as a correct value if we consider that $\mathrm{CMs}$ in our systems were more concentrated (50 g casein. $\mathrm{kg}^{-1}$ ) than in milk (about $25 \mathrm{~g}$ casein. $\mathrm{kg}^{-1}$ ) and suspended in HEPES buffer (and not in the continuous phase of milk).

In the suspension of cross-linked CMs, soluble calcium was lower than control CMs in all the range of $\mathrm{pH}$ studied, increasing from $0.5 \mathrm{mmol} . \mathrm{L}^{-1}$ at $\mathrm{pH} 7.1$ to 16.8 mmol. $\mathrm{L}^{-1}$ at $\mathrm{pH} 5.2$ (Fig. 3). One explanation of this difference in the calcium solubilization between control and cross-linked CMs could be related to difference of charged chemical groups of casein molecules. Indeed, our previous work (Nogueira Silva et al. 2014) showed that cross-linked CMs were more negatively charged than the control ones. Assuming that the cross-linking reaction inside the CMs was the same as on their surface, the interior of cross-linked CMs should be more negatively charged than that of control ones. This could be an explanation for the greater retention of calcium by the cross-linked CMs.

\subsubsection{Structural rearrangement}

Table 1 (comparison 2) recapitulates the modifications on the dimensional characteristics of immobilized control CMs from $\mathrm{pH} 7.1$ to 5.2. Shrinkage of control CMs was deduced by decreases of 17 and $52 \%$ of their $w$ and $h$, respectively. The shrinkage of control CMs was also observed by the reduction in the apparent $\theta$ (Table 1 -comparison 2), and it is also recognizable when images in Fig. 2a, b are compared with Fig. 4a, b. These results were in accordance with those reported by Moitzi et al. (2010), who employed a 3D light scattering instrument to study the size and structure of CMs on highly turbid samples, without dilution. They observed that CMs had a spherical shape with a denser core than periphery at $\mathrm{pH} 6.9$ (the external parts are rather loose), but at $\mathrm{pH} 5.2$, the size of CMs decreased and they were present as homogenous spheres. The reduction in size of CMs upon acidification was also verified by Ouanezar et al. (2012) using AFM for 

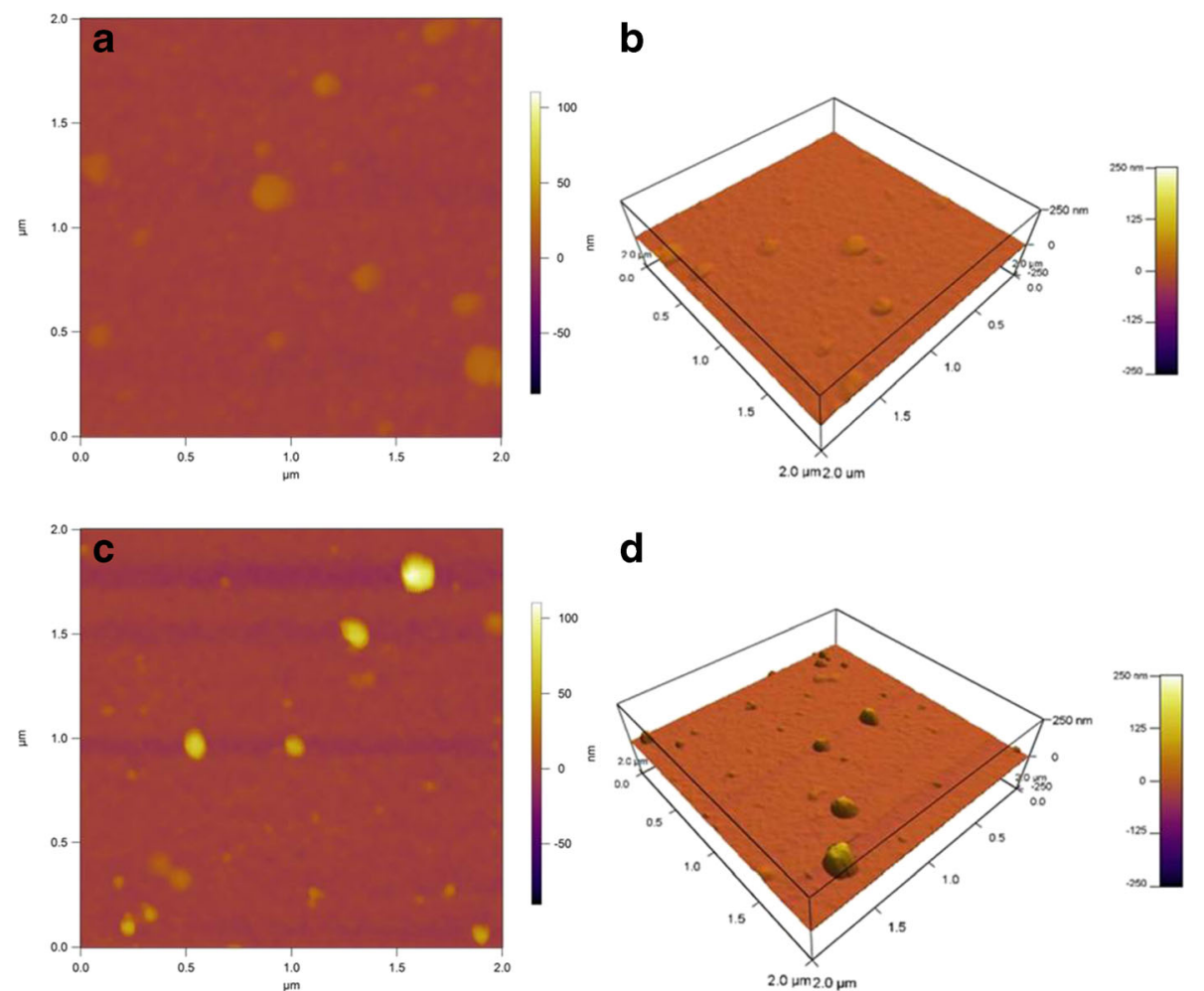

Fig. 4 AFM images of control CMs in $\mathbf{a} 2 \mathrm{D}$ and $\mathbf{b} 3 \mathrm{D}$ at pH 5.2 and cross-linked CMs in $\mathbf{c} 2 \mathrm{D}$ and $\mathbf{d}$ 3D at pH 5.2

observations of CMS in liquid and dry conditions. As the particles were immobilized before acidification, the authors also noticed a preferential shrink in the $h$ direction.

The shrinkage of control CMs upon acidification resulted from different dependent phenomena such as (i) solubilization of CCP which is one of the main structural component of CMs (Holt et al. 1998; De Kruif and Holt 2003), (ii) neutralization of acid residues of casein molecules by protons (Horne 2009), and (iii) the consequent changes in the molecular interactions between protein-protein and protein-water. Specifically, the reduction of the apparent $\theta$ suggests that control CMs exhibited lower elasticity in acid conditions. However, shrinkage (compressibility) puts a limit to the theory (Evangelopoulos et al. 2012). Uricanu et al. (2004) rather reported that the intrinsic elasticity of CMs was not dependent on $\mathrm{pH}$.

The effects of acidification at $\mathrm{pH} 5.2$ on the dimensional characteristics $(w, h$, and apparent $\theta$ ) of cross-linked CMs were negligible compared to $\mathrm{pH} 7.1$ (Table 1comparison 3). The comparison between Figs. 4c, d (acidified cross-linked CMs) and 2c, d (cross-linked CMs at pH 7.1) leads to the same conclusion. Two factors can explain the structural resistance of cross-linked CMs after acidification, (i) the covalent cross-linking of lysyl and arginyl residues made by GP (Nogueira Silva et al. 2014) and (ii) the higher retention of colloidal calcium in acid conditions (Fig. 3). Thereby, it was possible to maintain the structure of the $\mathrm{CMs}$ at $\mathrm{pH} 5.2$ as a result of the intramicellar cross-linking by GP. From this fact, it could be interesting to study the mechanical behavior of a gel formed by cross-linked CMs in acid environment. 


\subsubsection{Calcium solubilization}

The calcium-chelating agents like citrate interact with the ionic calcium $\left(\mathrm{Ca}^{2+}\right)$ in the continuous phase of milk or CM suspensions (Holt et al. 1981). In this way, they cause dissociation of $\mathrm{CaHPO}_{4}$ by disturbing the ionic equilibrium between $\mathrm{Ca}^{2+}$ and $\mathrm{HPO}_{4}{ }^{2-}$ (as explained in Sect. 3.2.1), inducing the solubilization of CCP.

The effects of demineralization by sodium citrate of control and cross-linked CMs on the solubilization of calcium are reported in Fig. 5. The concentration of soluble calcium increased as a function of the concentration of sodium citrate for both casein suspensions, but in different proportions. Similarly to the effects of acidification previously described (Fig. 3), solubilization of the colloidal calcium by citrate was higher for control CMs compared with cross-linked CMs in the range of citrate concentration employed (Fig. 5). At citrate concentration of $100 \mathrm{mmol} . \mathrm{L}^{-1}$, about 70 and $64 \%$ of the colloidal calcium were dissociated for control and cross-linked CMs, respectively (Fig. 5). This result confirmed that cross-linked CMs retained more colloidal calcium independently of the approach applied to solubilize the CCP.

\subsubsection{Structural rearrangement}

The solubilization of colloidal calcium by citrate induced changes on the molecular interactions within control and cross-linked CMs. In the presence of 100 mmol.L $\mathrm{L}^{-1}$ sodium citrate, the negative charges of the phosphoseryl residues were exposed, and then control CMs dissociated due to internal electrostatic repulsions (Lin et al. 1972; De Kruif and Holt 2003; Horne 2009). For this reason, determination of dimensional characteristics by AFM was not possible for control CMs. Conversely, cross-linked CMs were not dissociated in the presence of $100 \mathrm{mM}$ sodium citrate, and it was possible to analyze them by AFM (Fig. 6).

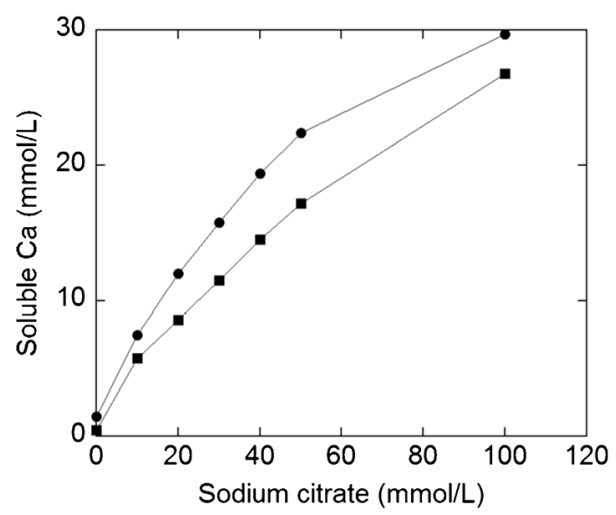

Fig. 5 Concentration of soluble calcium as a function of the concentration of sodium citrate added to micellar suspensions. Control (circle) and cross-linked (square) CMs 

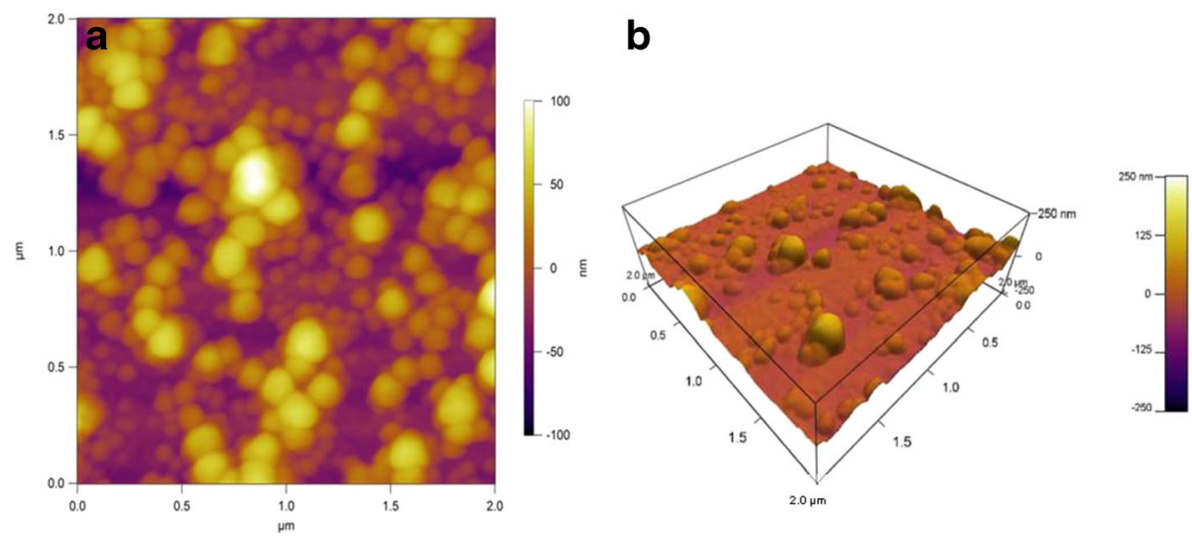

Fig. 6 AFM images of cross-linked CMs in a 2D and $\mathbf{b} 3 \mathrm{D}$ in the presence of $100 \mathrm{mmol} . \mathrm{L}^{-1}$ sodium citrate

Table 1 (comparison 4) shows the $w$ and $h$ dimensions and the apparent $\theta$ of crosslinked CMs before and after addition of $100 \mathrm{mmol}^{-1}$ of sodium citrate. The supramolecular organization of cross-linked CMs was modified by citrate addition, which can be perceived by the flattening of these particles, with a $24 \%$ increase in $w$ and a $15 \%$ decrease in $h$. As a matter of fact, cross-linked CMs swell after calcium chelation at neutral pH (Huppertz and de Kruif 2008; Nogueira Silva et al. 2014). In such environment, the protein chains within the demineralized particles are more hydrated than in non-demineralized ones. Consequently, the protein mesh is less compacted. We suppose that these conditions permitted a rearrangement of the structure of the cross-linked CMs in the presence of citrate. As a result, the apparent $\theta$ was reduced from $\sim 60^{\circ}$ to $\sim 50^{\circ}$ after demineralization. These modifications can be also seen in Fig. 6 as 2D and 3D images obtained by AFM. In addition, it is noteworthy that the apparent $\theta$ of demineralized cross-linked $\mathrm{CMs}\left(\sim 50^{\circ}\right)$ was higher than that determined for the control CMs $\left(\sim 40^{\circ}\right)$. This result underlines the fact that, even in the absence of CCP, the cross-linked CMs are more elastic than control CMs.

\section{Conclusion}

Cross-linked CMs were more structured and stable than native CMs in acid conditions and in the presence of citrate. On the one hand, analyses of the calcium solubilization revealed that this ion was more retained in the cross-linked CMs than in control CMs, independently of the approach used to solubilize the CCP. On the other hand, the AFM imaging was a useful tool to investigate structural changes of control and cross-linked CMs after their acidification or demineralization. By this method, it was shown that control CMs were deformed on immobilization and shrunk upon acidification at $\mathrm{pH}$ 5.2. The cross-linked CMs were also deformed on immobilization but at a lesser extent than control CMs. The acidification at pH 5.2 did not modify the cross-linked CMs. On the contrary, the demineralization by sodium citrate induced a rearrangement of the supramolecular structure of the cross-linked CMs. Although the observations were performed on isolated objects at dry conditions, the results illustrated the dynamic behavior of CMs even after cross-linking. 


\section{References}

Brulé G, Maubois JL, Fauquant J (1974) Étude de la teneur en éléments minéraux des produits obtenus lors de l'ultrafiltration du lait sur membrane. Lait 54:600-615

Dalgleish DG (2011) On the structural models of bovine casein micelles-review and possible improvements. Soft Matter 7:2265-2272

De Kruif CG, Holt C (2003) Casein micelle structure, functions and interactions. In: Fox PF, McSweeney PLH (eds) Adv. Dairy Chem. 1Proteins. Elsevier Academic Press, London, pp 233-276

Endo TOHR, Taguchi HEIH (1973) The constituents of Gardenia jasminoides geniposide and genipingentiobioside. Chem Pharm Bull (Tokyo) 21:2684-2688

Evangelopoulos AEAS, Glynos E, Madani-Grasset F, Koutsos V (2012) Elastic modulus of a polymer nanodroplet: theory and experiment. Langmuir 28:4754-4767

Fox PF (2003) Milk proteins: general and historical aspects. In: Fox PF, McSweeney PLH (eds) Advanced Dairy Chemistry: Volume 1: Proteins. Elsevier Academic Press, Kluver Academic Plenum Publishers New York, pp 1-48

Gaucheron F (2005) The minerals of milk. Reprod Nutr Dev 45:473-484

Gebhardt R, Holzmüller W, Zhong Q et al (2011) Structural ordering of casein micelles on silicon nitride micro-sieves during filtration. Colloid Surface B 88:240-245

Glantz M, Håkansson A, Lindmark Månsson H et al (2010) Revealing the size, conformation, and shape of casein micelles and aggregates with asymmetrical flow field-flow fractionation and multiangle light scattering. Langmuir 26:12585-12591

Helstad K, Rayner M, van Vliet T et al (2007) Liquid droplet-like behaviour of whole casein aggregates adsorbed on graphite studied by nanoindentation with AFM. Food Hydrocoll 21:726-738

Holt C (2004) An equilibrium thermodynamic model of the sequestration of calcium phosphate by casein micelles and its application to the calculation of the partition of salts in milk. Eur Biophys J 33:421-434

Holt C, Dalgleish DG, Jenness R (1981) Calculation of the ion equilibria in milk diffusate and comparison with experiment. Anal Biochem 113:154-163

Holt C, Timmins PA, Errington N, Leaver J (1998) A core-shell model of calcium phosphate nanoclusters stabilized by $\beta$-casein phosphopeptides, derived from sedimentation equilibrium and small-angle X-ray and neutron-scattering measurements. Eur J Biochem 252:73-78

Horne DS (2009) Chapter 5-casein micelle structure and stability. Milk Proteins - from expression to food. In Thompson A, and Boland M. Academic Press/Elsevier, Amsterdam, Boston, pp 133-162

Huppertz T, de Kruif CG (2008) Structure and stability of nanogel particles prepared by internal cross-linking of casein micelles. Int Dairy J 18:556-565

Le Graët Y, Brulé G (1993) Les équilibres minéraux du lait: influence du pH et de la force ionique. Lait 73:51-60

Lee SW, Lim J-M, Bhoo SH et al (2003) Colorimetric determination of amino acids using genipin from Gardenia jasminoides. Anal Chim Acta 480:267-274

Lin SHC, Leong SL, Dewan RK et al (1972) Effect of calcium ion on the structure of native bovine casein micelles. Biochemistry 11:1818-1821

Moitzi C, Menzel A, Schurtenberger P, Stradner A (2010) The pH induced sol-gel transition in skim milk revisited. A detailed study using time-resolved light and X-ray scattering experiments. Langmuir 27: 2195-2203. doi:10.1021/la102488g

Nguyen AV, Nalaskowski J, Miller JD (2003) The dynamic nature of contact angles as measured by atomic force microscopy. J Colloid Interface Sci 262:303-306

Nogueira Silva N, Saint Jalmes A, de Carvalho AF, Gaucheron F (2014) Development of casein microgels from cross-linking of casein micelles by genipin. Langmuir 30:10167-10175. doi:10.1021/1a502274b

Ouanezar M, Guyomarc'h F, Bouchoux A (2012) AFM imaging of milk casein micelles: evidence for structural rearrangement upon acidification. Langmuir 28:4915-4919. doi:10.1021/la3001448

Pierre A, Fauquant J, Le Graet Y et al (1992) Préparation de phosphocaséinate natif par microfiltration sur membrane. Lait 72:461-474

Schuck P, Piot M, Méjean S et al (1994) Déshydratation par atomisation de phosphocaséinate natif obtenu par microfiltration sur membrane. Lait 74:375-388

Tuinier R, De Kruif CG (2002) Stability of casein micelles in milk. J Chem Phys 117:1290

Uricanu VI, Duits MHG, Mellema J (2004) Hierarchical networks of casein proteins: an elasticity study based on atomic force microscopy. Langmuir 20:5079-5090

Walstra P, Wouters JTM, Geurts TJ (2010) Dairy science and technology, 2nd edn. Taylor \& Francis, Boca Raton 